\title{
Heterogeneous glycaemic and insulinaemic responses to oral glucose in non-diabetic men: interactions between duration of obesity, body fat distribution and family history of diabetes mellitus
}

\author{
S. Lemieux ${ }^{1}$, J.-P.Després ${ }^{1}$, A.Nadeau ${ }^{2}$, D.Prud'homme ${ }^{1}$, A. Tremblay ${ }^{1}$ and C.Bouchard $^{1}$ \\ ${ }^{1}$ Physical Activity Sciences Laboratory, Laval University, and \\ ${ }^{2}$ Diabetes Research Unit, Laval University Medical Center, Ste-Foy, Québec, Canada
}

\begin{abstract}
Summary. The interaction between environmental and genetic factors in the alterations of glucose-insulin homeostasis was studied in 104 non-diabetic men. Family history of diabetes mellitus was used as an index of genetic predisposition to diabetes. Body composition was measured by underwater weighing whereas subcutaneous and visceral adipose tissue areas were measured at the abdominal and femoral levels by computed tomography. The sample was first divided into two groups. The first group included subjects with "normal" glycaemic and insulinaemic responses during a $75 \mathrm{~g}$ oral glucose tolerance test. The second group was composed of subjects either with a high glucose response or high insulin response or both. Men included in the second group were different from the "normal" subjects for almost all body fatness variables. They also presented a prevalence of a positive family history of diabetes which was significantly higher than "normal" subjects. The second group was then divided into three distinct subgroups based on insulin and glucose responses of the subjects during the oral glucose tolerance test. Subjects with high insulin but "normal" glucose responses were characterized by significantly higher levels of total body fat and deep abdominal adipose tissue when compared to the "normal" group $(p<0.05)$. Men with both high insulinaemic and glycaemic responses displayed higher body fatness values
\end{abstract}

and higher deep and subcutaneous abdominal adipose tissue areas $(p<0.05)$ in comparison with "normal" subjects. They also had a higher body mass index at age 20 years than control subjects and subjects with high insulin but "normal" glucose responses. In contrast, subjects with "normal" insulin but with high glucose responses were not different from the "normal" group with regard to body fat and adipose tissue areas. These results show the heterogeneous origin of altered glucose-insulin homeostasis in non-diabetic men. Finally, subjects in the altered glucose-insulin homeostasis group with no family history of diabetes displayed a higher body mass index at age 20 years $(p<0.05)$ in comparison with subjects who had a positive family history of the disease. They also presented a greater abdominal-to-thigh fat ratio measured by computed tomography. These results suggest that in men with alterations of glucose-insulin homeostasis, the relationship of body fat distribution to glucose tolerance and plasma insulin levels is different in those with no family history of diabetes than in subjects with a positive family history of diabetes.

Key words: Genetic susceptibility, obesity, Type 2 (non-insulin-dependent) diabetes mellitus, glucose tolerance, body fat distribution.
It is well established that environmental and genetic risk factors interact in the aetiology of Type 2 (non-insulin-dependent) diabetes mellitus [1-4]. The importance of environmental factors in the pathogenesis of Type 2 diabetes is evident from the increased prevalence of the disease observed during this century [4-6]. In this regard, the WHO Expert Committee on Diabetes has concluded that increased adiposity appears to be the most powerful risk factor for Type 2 diabetes [7]. Recently, emphasis has been placed on the importance of regional body fat distribution [8-11]. In fact, several studies have provided evidence that a preferential accumulation of fat in the trunk, especially abdominal fat deposition, was more closely associated with the development of metabolic alterations such as hyperinsulinaemia, insulin resistance, impaired glucose tolerance and Type 2 diabetes than obesity itself [12-16]. There are also data suggesting that the duration and the age of onset of obesity may be important in determining the risk of developing Type 2 diabetes $[17,18]$.

Genetic factors also play an important role in the development of metabolic alterations leading to Type 2 diabetes. Results from Köbberling and co-workers [19] indicate that $43 \%$ of first-degree relatives of Type 2 diabetic patients will eventually develop the disease. In addition, the concordance for Type 2 diabetes between monozygotic twins varies between 60 to almost $100 \%[1,20,21]$. 
Furthermore, Fujimoto and collaborators [22] have demonstrated that the relationships between diabetes and general adiposity as well as body fat distribution were more apparent in men without a family history of diabetes than in those with a family history.

Insulin resistance (evidenced by hyperinsulinaemia with or without hyperglycaemia) or defective insulin secretion (which may be suspected with hyperglycaemia) are two possible factors that have been suggested in the pathogenesis of Type 2 diabetes [23]. However, the study of the interactions between family history of diabetes, adipose tissue distribution, obesity and its duration, and glucose tolerance and insulin levels has never, to the best of our knowledge, been performed in non-diabetic men characterized by low or high insulin responses.

The aim of the present study was therefore to search for the potential determinants of either hyperglycaemia or hyperinsulinaemia or both in a group of non-diabetic men in an attempt to obtain clues to the pathogenesis of Type 2 diabetes. Moreover, we wanted to further investigate the potential interactions between family history of diabetes, body fat distribution, duration of obesity and glucose-insulin homeostasis in a sample of non-diabetic men.

\section{Subjects and methods}

\section{Subjects}

One hundred and four men of French ancestry, aged 20 to 42 years, were recruited through the media to participate in this study, which was approved by the Medical Ethics Committee of Laval University. Before entering the study, participants were subjected to a complete medical examination and were asked to sign an informed consent document. All these men were apparently healthy, i.e. free from overt diseases requiring treatment (diabetes, hypercholesterolaemia, coronary heart disease). However, 12 men were diagnosed as having impaired glucose tolerance according to the classification of the National Diabetes Data Group [24].

\section{Body composition and anthropometry}

Body density was measured by the hydrostatic weighing technique [25] and the mean of six measurements was used in the calculation of body density. Pulmonary residual volume was measured before immersion in the hydrostatic tank, using the helium dilution method of Meneely and Kaltreider [26]. Percent body fat was derived from body density using the equation of Siri [27]. Waist and hip circumferences were measured following the procedures recommended by the Airlie Conference [28], and the waist-to-hip ratio was calculated.

\section{Computed tomography}

Computed tomography (CT) was performed on a Siemens Somatom DRH scanner (Erlanger, FRG) by using the procedure of Sjöström et al. [29] as previously described [30]. Briefly, subjects were examined in the supine position with both arms stretched above their heads. CT scans were performed at the abdominal (between LA and L5 vertebraes) and at the femoral (mid-distance between the knee joint and the iliac crest) levels, using a radiograph of the skeleton as a reference to establish the position of the scan to the nearest millimeter. Total fat areas were calculated by delineating these areas with a graph pen and then computing the adipose tissue surfaces using an attenuation range of -30 to -190 Hounsfield units (HU) $[29,31]$. The intra-abdominal fat area was measured by drawing a line within the muscle wall surrounding the abdominal cavity. The abdominal subcutaneous fat area was calculated by subtracting the amount of intra-abdominal fat from the total fat area.

\section{Oral glucose tolerance test}

A $75 \mathrm{~g}$ oral glucose tolerance test (OGTT) was performed the morning after an overnight fast. Blood samples were collected in EDTA and Trasylol-containing tubes (Miles Pharmaceuticals, Rexdale, Ontario, Canada) through a venous catheter placed in an antecubital vein at $-15,0,15,30,45,60,90,120,150$, and $180 \mathrm{~min}$ for the determination of plasma glucose and insulin concentrations. Plasma glucose was measured enzymatically [32], whereas plasma insulin was measured by radioimmunoassay with polyethylene glycol separation [33]. The total glucose and insulin areas under the curve during the OGTT were determined with the trapezoid method. Glucose and insulin responses were calculated by subtracting the fasting area (fasting level over $180 \mathrm{~min}$ ) from the total area under the curve.

\section{Classification of subjects into "normal" and altered glucose-insulin homeostasis subgroups}

Subjects were first divided into two groups based upon their insulin and their glucose responses during the OGTT. The first group was arbitrarily composed of men with insulin and glucose responses less than or equal to the $75^{\text {th }}$ percentile of the total sample for both variables. The remaining subjects (altered glucose-insulin homeostasis) were subdivided into three distinct subgroups. The first subgroup was composed of subjects with insulin responses above the $75^{\text {th }}$ percentile (high insulin) but with glucose responses below the $75^{\text {th }}$ percentile ("normal" glucose). The second subgroup included subjects with both insulin and glucose responses greater than the $75^{\text {th }}$ percentile (high insulin, high glucose). Finally, the third subgroup was characterized by subjects with insulin responses below the $75^{\text {th }}$ percentile ("normal" insulin) but with glucose responses greater than the $75^{\text {th }}$ percentile (high glucose).

\section{Family history of diabetes}

Family history of diabetes was used as an index of genetic predisposition to diabetes [22]. Family history was considered positive when subjects reported that at least one full sibling or parent had diabetes. Family history was considered negative when the subject reported that none of his siblings and neither parent had diabetes.

\section{Body weight history}

Each subject was questionned about his weight at age 20 . The change in weight since age 20 was thus obtained by subtracting the weight at 20 years from the current weight. The weight at age 20 and the change in weight provided us with a simple indicator of the body weight history for each subject.

\section{Statistical analysis}

The Student's $t$-test was used to compare "normal" subjects to those with alterations in glucose-insulin homeostasis. The same statistical test was used to compare subjects with and without a positive family history of diabetes. One-way analysis of variance was used to compare the group with "normal" glucose-insulin homeostasis with sub- 


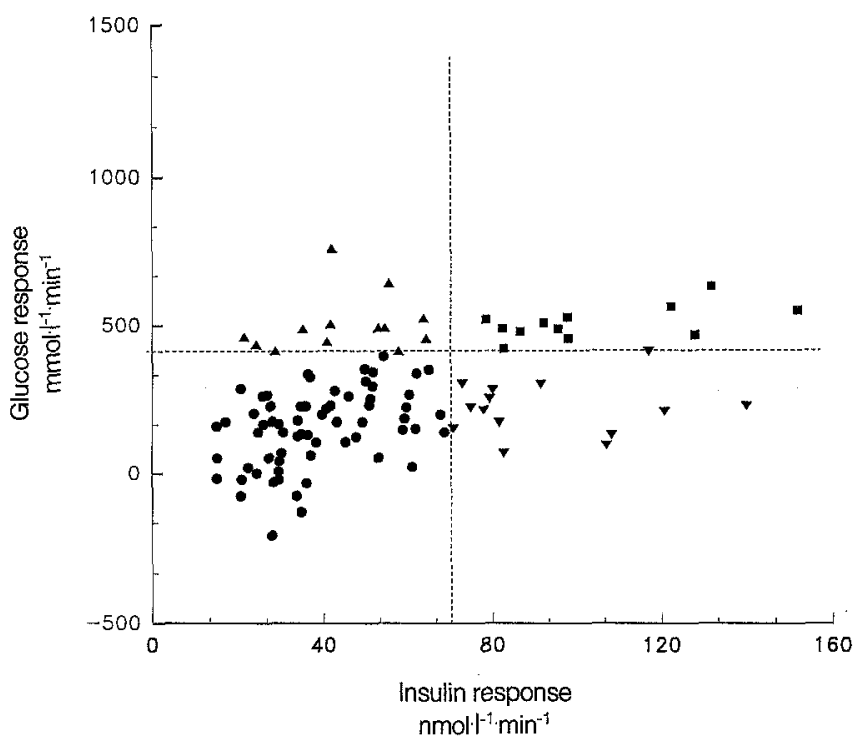

Fig. 1. Relationship between plasma glucose and insulin responses during a $75 \mathrm{~g}$ oral glucose tolerance test in a sample of 104 nondiabetic men. Dotted lines represent the $75^{\text {th }}$ percentile for both glucose and insulin responses. A negative value indicates that plasma glucose levels following the oral glucose administration eventually fell below basal values during the 180 -min test, thereby generating a negative glucose response. $\bullet$, normal glucose-insulin homeostasis; $\boldsymbol{\nabla}$, high insulin, normal glucose responses; $\mathbf{\square}$, high insulin, high glucose responses; $\boldsymbol{\Delta}$, normal insulin, high glucose responses

groups of men showing disturbances in glucose-insulin homeostasis. When this procedure revealed the presence of a significant difference, the Duncan multiple range test was used for posteriori comparisons. Chi-square test was used to compare the prevalence of positive family history of diabetes among the group with "normal" glucose-insulin homeostasis and subjects with disturbed glucose-insulin homeostasis. All statistical analyses were performed with the SAS (Statistical Analysis System) statistical package (SAS Institute, Cary, NC, USA).

\section{Results}

The relationship between plasma glucose and insulin responses to a $75 \mathrm{~g}$ OGTT in the overall sample of 104 nondiabetic men is shown in Figure 1. Most of the subjects $(62.5 \%)$ had glucose and insulin responses which were considered to be "normal". Since we studied a sample of non-diabetic subjects, "normality" was arbitrarily considered as a value less than or equal to the $75^{\text {th }}$ percentile of the total sample distribution for both variables. All 12 subjects who were diagnosed as having impaired glucose tolerance were found in the group with altered glucose-insulin homeostasis.

Morphological and metabolic characteristics of subjects with "normal" insulin and glucose responses, in comparison with the sample of men with either high insulin or high glucose responses or both, are presented in Table 1. Except for the abdominal visceral to subcutaneous adipose tissue ratio, all body fatness variables were significantly different between the two groups. Subjects with alterations in glucose-insulin homeostasis displayed significantly higher plasma glucose and insulin levels in the fasting state, as well as a higher ratio of plasma insulin to glucose areas during the OGTT.

Subjects with altered glucose-insulin homeostasis were then further subdivided into three subgroups based on their plasma insulin and glucose responses measured during the OGTT. Table 2 presents comparisons among the four subgroups obtained for morphological and metabolic variables. Men with a high glucose response but with "normal" insulin levels during the OGTT were not significantly different from "normal" subjects with respect to their morphological variables. Subjects with high insulin responses but with "normal" glucose responses during the OGTT had higher percentage of body fat, body mass index (BMI), waist-to-hip ratio and visceral fat levels $(p<0.05)$ compared to "normal" subjects. Finally, the subgroup of men with both elevated glucose and insulin responses had higher BMI, percentage of body fat, waistto-hip ratio, as well as greater abdominal adipose tissue area and abdominal to femoral ratio values than "normal" men $(p<0.05)$. Furthermore, men with both high insulin and glucose responses had significantly higher mean BMI at age 20 years $(p<0.05)$ than control subjects. They also had higher BMI at age 20 years than men characterized by "normal" glucose and elevated insulin responses during the OGTT $(p<0.05)$.

A significantly greater proportion of subjects characterized by elevated plasma glucose or insulin responses or

Table 1. Morphological and metabolic variables in normal men and in men with altered glucose-insulin homeostasis

\begin{tabular}{|c|c|c|}
\hline & $\begin{array}{l}\text { Normal } \\
\text { insulin-glucose } \\
\text { homeostasis } \\
(n=65)\end{array}$ & $\begin{array}{l}\text { Altered } \\
\text { insulin-glucose } \\
\text { homeostasis } \\
(n=39)\end{array}$ \\
\hline$\overline{\text { Age (years) }}$ & $33.54 \pm 6.14$ & $35.49 \pm 4.85$ \\
\hline BMI at 20 years $\left(\mathrm{kg} / \mathrm{m}^{2}\right)$ & $23.22 \pm 2.68$ & $24.39 \pm 2.90$ \\
\hline Change in weight since age $20(\mathrm{~kg})$ & $9.60 \pm 8.83$ & $13.92 \pm 7.44^{\mathrm{a}}$ \\
\hline $\mathrm{BMI}\left(\mathrm{kg} / \mathrm{m}^{2}\right)$ & $25.72 \pm 4.00$ & $28.34 \pm 3.41^{\mathrm{b}}$ \\
\hline Body fat $(\%)$ & $22.08 \pm 8.54$ & $27.08 \pm 7.86^{b}$ \\
\hline WHR & $0.90 \pm 0.07$ & $0.96 \pm 0.06^{\mathrm{d}}$ \\
\hline \multicolumn{3}{|l|}{ Computed tomography } \\
\hline Subcutaneous $\left(\mathrm{cm}^{2}\right)$ & $223.93 \pm 102.67$ & $293.58 \pm 80.93^{b}$ \\
\hline Visceral $\left(\mathrm{cm}^{2}\right)$ & $103.18 \pm 35.31$ & $148.33 \pm 50.93^{\mathrm{d}}$ \\
\hline Visceral: subcutaneous & $0.51 \pm 0.18$ & $0.52 \pm 0.16$ \\
\hline Midthigh fat area $\left(\mathrm{cm}^{2}\right)$ & $193.80 \pm 77.07$ & $226.10 \pm 56.93^{\mathrm{a}}$ \\
\hline Abdominal: midthigh (total) & $1.72 \pm 0.41$ & $1.97 \pm 0.36^{\mathrm{b}}$ \\
\hline \multicolumn{3}{|l|}{ Fasting } \\
\hline Glucose $(\mathrm{mmol} / \mathrm{l})$ & $5.0 \pm 0.4$ & $5.3 \pm 0.6^{\mathrm{a}}$ \\
\hline Insulin $(\mathrm{pmol} / \mathrm{l})$ & $65 \pm 20$ & $91 \pm 36^{\mathrm{c}}$ \\
\hline \multicolumn{3}{|l|}{ OGTT } \\
\hline $\begin{array}{l}\text { Glucose resp. }\left(\mathrm{mmol} \cdot \mathrm{I}^{-1}\right. \\
\left.\min ^{-1}\right) \times 10^{-3}\end{array}$ & $0.15 \pm 0.13$ & $0.40 \pm 0.16^{\mathrm{d}}$ \\
\hline $\begin{array}{l}\text { Insulin resp. }\left(\mathrm{pmol} \cdot \mathrm{l}^{-1}\right. \\
\left.\min ^{-1}\right) \times 10^{-3}\end{array}$ & $38.55 \pm 14.29$ & $80.34 \pm 32.46^{\mathrm{d}}$ \\
\hline Insulin area: glucose area & $47.4 \pm 13.1$ & $72.7 \pm 29.5^{\mathrm{d}}$ \\
\hline
\end{tabular}

Number of subjects for computed tomography variables is 54 for the normal glucose-insulin homeostasis group.

a Significantly different from normal subjects, $p<0.05$; ${ }^{\mathrm{b}} p<0.01$; ${ }^{c} p<0.001 ;{ }^{\mathrm{d}} p<0.0001$

Data are means \pm SD. BMI, Body mass index; WHR, waist-to-hip ratio; OGTT, oral glucose tolerance test 
Table 2. Morphological and metabolic variables in men with high insulin and normal glucose responses; high insulin and high glucose responses, and normal insulin and high glucose responses in comparison with control men

\begin{tabular}{|c|c|c|c|c|}
\hline & $\begin{array}{l}\text { Control } \\
\text { men } \\
(n=65)\end{array}$ & $\begin{array}{l}\text { High insulin } \\
\text { normal glucose } \\
\text { responses } \\
(n=13)\end{array}$ & $\begin{array}{l}\text { High insulin } \\
\text { high glucose } \\
\text { responses } \\
(n=13)\end{array}$ & $\begin{array}{l}\text { Normal insulin } \\
\text { high glucose } \\
\text { responses } \\
(n=13)\end{array}$ \\
\hline Age (years) & $33.54 \pm 6.14$ & $37.07 \pm 2.87$ & $36.75 \pm 3.22$ & $32.65 \pm 6.54^{b}$ \\
\hline BMI at 20 years $\left(\mathrm{kg} / \mathrm{m}^{2}\right)$ & $23.22 \pm 2.68$ & $23.18 \pm 2.55$ & $25.86 \pm 3.50^{\mathrm{a}, \mathrm{b}}$ & $24.69 \pm 2.03$ \\
\hline $\begin{array}{l}\text { Change in weight } \\
\text { since age } 20(\mathrm{~kg})\end{array}$ & $9.60 \pm 8.83$ & $15.72 \pm 7.07$ & $14.30 \pm 6.50$ & $10.64 \pm 8.65$ \\
\hline $\mathrm{BMI}\left(\mathrm{kg} / \mathrm{m}^{2}\right)$ & $25.72 \pm 4.00$ & $28.47 \pm 2.68^{a}$ & $30.47 \pm 1.53^{\mathrm{a}}$ & $25.89 \pm 4.09^{c}$ \\
\hline Body fat $(\%)$ & $22.08 \pm 8.54$ & $28.57 \pm 3.84^{\mathrm{a}}$ & $30.50 \pm 4.61^{\mathrm{a}}$ & $21.75 \pm 11.00^{\mathrm{b}, \mathrm{c}}$ \\
\hline WHR & $0.90 \pm 0.07$ & $0.96 \pm 0.05^{\mathrm{a}}$ & $0.99 \pm 0.03^{\mathrm{a}}$ & $0.93 \pm 0.07^{\circ}$ \\
\hline \multicolumn{5}{|l|}{ Computed tomography } \\
\hline \multicolumn{5}{|l|}{ Abdominal fat areas } \\
\hline Subcutaneous $\left(\mathrm{cm}^{2}\right)$ & $223.93 \pm 102.67$ & $265.82 \pm 72.30$ & $327.87 \pm 67.10^{\mathrm{a}}$ & $284.16 \pm 99.91$ \\
\hline Visceral $\left(\mathrm{cm}^{2}\right)$ & $103.18 \pm 35.31$ & $146.09 \pm 42.56^{\mathrm{a}}$ & $174.62 \pm 50.18^{\mathrm{a}}$ & $113.59 \pm 45.16^{\mathrm{b}, \mathrm{c}}$ \\
\hline Midthigh fat area $\left(\mathrm{cm}^{2}\right)$ & $193.80 \pm 77.07$ & $209.41 \pm 39.68$ & $249.20 \pm 56.11$ & $216.84 \pm 72.62$ \\
\hline Abdominal: midthigh (total) & $1.72 \pm 0.41$ & $1.97 \pm 0.26$ & $2.06 \pm 0.41^{a}$ & $1.85 \pm 0.41$ \\
\hline \multicolumn{5}{|l|}{ Fasting } \\
\hline Glucose $(\mathrm{mmol} / \mathrm{l})$ & $5.0 \pm 0.4$ & $5.4 \pm 0.4^{\mathrm{a}}$ & $5.4 \pm 0.6^{\mathrm{a}}$ & $5.0 \pm 0.7^{\mathrm{b}, \mathrm{c}}$ \\
\hline Insulin (pmol/l) & $65 \pm 20$ & $101 \pm 30^{\mathrm{a}}$ & $108 \pm 40^{\mathrm{a}}$ & $63 \pm 19^{\mathrm{b}, \mathrm{c}}$ \\
\hline \multicolumn{5}{|l|}{ OGTT } \\
\hline Glucose resp. $\left(\mathrm{mmol} \cdot \mathrm{I}^{-1} \cdot \mathrm{min}^{-1}\right) \times 10^{-3}$ & $0.15 \pm 0.13$ & $0.20 \pm 0.07$ & $0.50 \pm 0.06^{\mathrm{a}, \mathrm{b}}$ & $0.50 \pm 0.10^{\mathrm{a}, \mathrm{b}}$ \\
\hline Insulin resp. $\left(\mathrm{pmol} \cdot 1^{-1} \cdot \mathrm{min}^{-1}\right) \times 10^{-3}$ & $38.55 \pm 14.29$ & $91.28 \pm 21.25^{\mathrm{a}}$ & $104.95 \pm 22.84^{\mathrm{a}, \mathrm{b}}$ & $44.81 \pm 14.52^{\mathrm{b}, \mathrm{c}}$ \\
\hline Insulin area: glucose area & $47.4 \pm 13.1$ & $93.7 \pm 24.4^{\mathrm{a}}$ & $84.0 \pm 15.4^{\mathrm{a}}$ & $40.4 \pm 13.4^{\mathrm{b}, \mathrm{c}}$ \\
\hline
\end{tabular}

Number of subjects for computed tomography variables is 54 for the normal glucose-insulin homeostasis group.

${ }^{a}$ Significantly different from control men, $p<0.05$; ${ }^{\mathrm{b}}$ significantly different from high insulin and normal glucose responses subgroup,

$p<0.05 ;{ }^{c}$ significantly different from high insulin and high glucose responses subgroup, $p<0.05$

Data are means \pm SD. BMI, body mass index; WHR, waist-to-hip ratio; OGTT, oral glucose tolerance test

both, had a positive family history of diabetes than men with "normal" values for both glucose and insulin responses during the OGTT ( $28 \%$ vs $11 \%, \chi^{2}=4.68$, $p<0.05$ ).

Finally, Table 3 compares subjects with and without a family history of diabetes within the group with either altered glucose or insulin responses or both. These results revealed that men with no family history of diabetes showed higher BMI values at age 20 years, and higher abdominal to femoral adipose tissue ratio $(p<0.05)$ than subjects with a family history of the disease. Men with a positive family history displayed higher plasma glucose levels in the fasting state $(p<0.05)$ than subjects with a negative family history.

\section{Discussion}

The aetiology of Type 2 diabetes has been the topic of several investigations and the reasons for its heterogeneity are only partly understood. Obesity, particularly abdominal obesity, has been proposed as being a major risk factor for the development of Type 2 diabetes [12-16]. The duration of obesity is also an important factor in the pathophysiology of Type 2 diabetes $[17,18]$. Nevertheless, obesity alone cannot totally explain the prevalence of diabetes, and genetic predisposition is also an important element in the development of the disease. In this regard, studies in identical twins have shown concordance for Type 2 diabetes even when obesity was not present [34]. In addi- tion, a possible autosomal dominant inheritance pattern in Nauruans [35] and Pima Indians [36] has been proposed, clearly indicating that obesity is not the only risk factor in the development of Type 2 diabetes. However, few studies have demonstrated the interactions between genetic susceptibility, body fat distribution, obesity and its duration in the aetiology of metabolic disturbances which may lead to Type 2 diabetes.

In the present study, we reported that subjects with altered glycaemic or insulinaemic responses had higher values for almost all body fatness variables when compared to "normal" subjects. We have also examined the role of family history of diabetes in our sample. The prevalence of diabetes in relatives of subjects with abnormal glucose-insulin homeostasis was significantly higher than in "normal" subjects. This observation was not surprising as many studies have demonstrated that obesity and genetic susceptibility are two major risk factors leading to metabolic alterations associated with the development of Type 2 diabetes [1-6, 19-21]. Furthermore, all 12 subjects who were diagnosed as having impaired glucose tolerance were found in the group with altered glucose-insulin homeostasis, characterized by high adiposity values and a high prevalence of family history of diabetes. These results further suggested that this group of men was at increased risk of developing Type 2 diabetes.

Men with altered plasma glucose or insulin responses were also further divided into three subgroups based on their glycaemic and insulinaemic responses observed during the OGTT. Both subgroups with high insulin respons- 
Table 3. Morphological and metabolic variables among nondiabetic men with alterations in glucose-insulin homeostasis as a function of presence or absence of family history of diabetes

\begin{tabular}{|c|c|c|}
\hline & $\begin{array}{l}\text { Presence of a } \\
\text { family history } \\
(n=11)\end{array}$ & $\begin{array}{l}\text { Absence of a } \\
\text { family history } \\
(n=28)\end{array}$ \\
\hline Age (years) & $35.45 \pm 4.95$ & $35.50 \pm 4.90$ \\
\hline BMI at 20 years $\left(\mathrm{kg} / \mathrm{m}^{2}\right)$ & $22.64 \pm 2.71$ & $25.26 \pm 2.64^{2}$ \\
\hline Change in weight since age $20(\mathrm{~kg})$ & $15.65 \pm 7.34$ & $13.02 \pm 7.52$ \\
\hline $\mathrm{BMI}\left(\mathrm{kg} / \mathrm{m}^{2}\right)$ & $27.36 \pm 2.88$ & $28.74 \pm 3.57$ \\
\hline Body fat (\%) & $26.81 \pm 6.67$ & $27.19 \pm 8.41$ \\
\hline WHR & $0.96 \pm 0.04$ & $0.96 \pm 0.06$ \\
\hline \multicolumn{3}{|l|}{ Computed tomography } \\
\hline \multicolumn{3}{|l|}{ Abdominal fat areas } \\
\hline Subcutaneous $\left(\mathrm{cm}^{2}\right)$ & $264.90 \pm 87.91$ & $305.05 \pm 76.82$ \\
\hline Visceral $\left(\mathrm{cm}^{2}\right)$ & $138.32 \pm 45.90$ & $152.33 \pm 53.15$ \\
\hline Visceral: subcutaneous & $0.56 \pm 0.21$ & $0.50 \pm 0.14$ \\
\hline Midthigh fat area $\left(\mathrm{cm}^{2}\right)$ & $230.34 \pm 64.40$ & $224.40 \pm 55.01$ \\
\hline Abdominal: midthigh (total) & $1.77 \pm 0.25$ & $2.05 \pm 0.37^{\mathrm{a}}$ \\
\hline \multicolumn{3}{|l|}{ Fasting } \\
\hline Glucose $(\mathrm{mmol} / \mathrm{l})$ & $5.6 \pm 0.6$ & $5.2 \pm 0.5^{\mathrm{a}}$ \\
\hline Insulin $(\mathrm{pmol} / \mathrm{l})$ & $76 \pm 21$ & $96 \pm 39$ \\
\hline \multicolumn{3}{|l|}{ OGTT } \\
\hline Glucose response (mmol. & & \\
\hline $\left.\mathrm{I}^{-1} \cdot \min ^{-1}\right) \times 10^{-3}$ & $0.35 \pm 0.19$ & $0.42 \pm 0.15$ \\
\hline $\begin{array}{l}\text { Insulin response }\left(\mathrm{pmol} \cdot 1^{-1}\right. \\
\left.\min ^{-1}\right) \times 10^{-3}\end{array}$ & $77.53 \pm 26.50$ & $81.45 \pm 34.91$ \\
\hline Insulin area: glucose area & $69.5 \pm 26.4$ & $74.0 \pm 31.0$ \\
\hline
\end{tabular}

a Significantly different from the mean in subjects with a family history of diabetes, $p<0.05$

Data are mean \pm SD. BMI, body mass index; WHR, waist-to-hip ratio; OGTT, oral glucose tolerance test

es showed greater total adiposity and abdominal adiposity than the "normal" group. These results are concordant with the notion that deep abdominal adipose tissue area is an important correlate of metabolic alterations, such as insulin resistance and hyperinsulinaemia, potentially leading to Type 2 diabetes in some patients [37-40]. However, subjects with high abdominal adiposity were heterogeneous in regard to their insulinaemic and glycaemic responses. A subgroup of men was able to compensate insulin resistance by increased insulinaemia (high insulin-"normal" glucose responses) whereas the other subgroup could not fully compensate as they displayed high glycaemic responses (high insulin-high glucose responses). Although no difference in current body fatness and body fat distribution were noted among these two groups, hyperinsulinaemic men with high glucose responses had higher BMI values at age 20 years than hyperinsulinaemic men with "normal" glycaemic responses. Although our cross-sectional observations have obvious limitations and should be carefully discussed, results of the present study are concordant with the notion that the evolution of obesity to diabetes develops through successive phases $[41-44]$. The difference in the duration of obesity that we found is consistent with the sequence of events that have been proposed for the evolution of obesity to Type 2 diabetes [45]. In addition, the subgroup represented by subjects with "normal" insulin but with high glucose responses was not significantly different from the "normal" group with regard to body fatness vari- ables. These results indicate that the major factor responsable for the higher glycaemic response in this subgroup may not be obesity or visceral fat deposition and that a major role for genetic susceptibility should be considered as a likely possibility in this subgroup. Unfortunately, because of the restricted number of subjects in each subgroup, we were not able to demonstrate statistically significant differences among the three subgroups with altered glucose-insulin homeostasis regarding the prevalence of genetic predisposition to diabetes.

Therefore, the three subgroups of men with various disturbances in their glucose-insulin homeostasis did not show similar differences when compared to the "normal" group, indicating the heterogeneous origin of altered glycaemic and insulinaemic responses noted in these nondiabetic men. To our knowledge, it is the first time that such comparisons have been performed within a sample of non-diabetic subjects with different alterations in glucose and insulin responses. We are, however, fully aware that "normality" regarding glucose and insulin responses, as defined by the $75^{\text {th }}$ percentile, was arbitrarily evaluated. However, since we have studied a sample of non-diabetic subjects, these results suggest that there are significant interactions among risk factors for Type 2 diabetes in the determination of heterogeneous glycaemic and insulinaemic responses in non- or pre-diabetic men.

The sample of men with altered glucose-insulin homeostasis was further examined regarding family history of diabetes. Subjects with a positive family history of the disease were compared to those with no family history. Subjects without family history of diabetes displayed significantly higher BMI values at age 20 years and abdominal to femoral adipose tissue ratio measured by CT in comparison with subjects with a positive family history of diabetes. These results suggest that disturbances in body fat distribution, obesity and its duration were more strongly associated with the development of alterations in glucose-insulin homeostasis in subjects with no family history of diabetes. These results are concordant with the observations of Fujimoto et al. [22] who have studied the role of family history in the relation of body weight and body fat distribution to diabetes. They reported that the relationship of adiposity to diabetes was stronger when the family history of diabetes was negative, suggesting that environmental factors that lead to increased adiposity are important in the genesis of Type 2 diabetes when no family history of diabetes is found. However, among individuals with a positive family history of diabetes, our results indicate that the development of Type 2 diabetes may not require obesity or high levels of visceral adipose tissue. At this point, we are not able to determine which of our subjects are at increased risk of developing Type 2 diabetes among our group of 39 men with altered glucose-insulin homeostasis. Among these subjects with altered glucoseinsulin homeostasis, although men with a positive family history did not show substantial alterations in body fat distribution when compared to men with no family history, we cannot conclude that men with positive family history were at lower risk of developing Type 2 diabetes considering the important role played by genetic susceptibility in the development of metabolic alterations potentially 
leading to Type 2 diabetes. This statement is supported by our data showing prevalence of a positive family history to be significantly greater in the group with altered glucoseinsulin homeostasis, as compared to the "control" group. In addition, men with a family history of diabetes displayed higher plasma glucose levels in the fasting state, suggesting that metabolic alterations predictive of an increased risk of Type 2 diabetes are present. In these men, genetic susceptibility seems to reduce the threshold of body fatness and abdominal fat deposition above which alterations in glucose-insulin homeostasis potentially leading to Type 2 diabetes are observed.

In summary, we have shown that non-diabetic subjects with altered glucose-insulin homeostasis were different from "normal" subjects with regard to many morphological and metabolic variables. Men with alterations in glucose-insulin homeostasis also presented a significantly greater prevalence of positive family history of diabetes than "normal" subjects. These men with alterations in glucose-insulin metabolism were, however, heterogeneous with regard to glycaemic and insulinaemic responses. This heterogeneity was partly attributed to differences in morphological variables and in the duration of obesity. Furthermore, we have also found that genetic susceptibility, assessed in the present study by the family history of diabetes, was an important factor in determining the heterogeneity of altered glucose-insulin responses, even in a sample of non-diabetic men. In fact, we found significant differences for body fat distribution and duration of obesity when subjects with a positive family history of diabetes were compared to those without a family history of the disease. These results suggest that genetic susceptibility, duration of obesity and regional body fat distribution may interact in the aetiology of altered insulinaemic and glycaemic responses, which could eventually lead to Type 2 diabetes.

Acknowledgements. The authors are grateful to the subjects in this study for their excellent collaboration and to the dedicated staff of the Physical Activity Sciences Laboratory and the Diabetes Research Unit. Sincere thanks are expressed to Ms. J. Maheux, J. Hovington, M. Marcotte, Mr. H. Bessette and C. Leblanc for their help in the collection and analysis of the data. The dedicated work of Ms. Y. Montreuil, M. Martin and R. Duchesne is also acknowledged. This study was supported by the Canadian Diabetes Association, the Medical Research Council (MRC) of Canada and by the Fonds de la Recherche en Santé du Québec (FRSQ). J.P.D. is an FRSQ scholar whereas S.L. is the recipient of an MRC fellowship.

\section{References}

1. Leslie RDG, Pyke DA (1987) Genetics of diabetes. In: Alberti KGMM, Krall LP (eds) The Diabetes Annual 3. Elsevier, Amsterdam, pp 39-54

2. Zimmet P, Dowse G, LaPorte R, Finch C, Moy C (1989) Epidemiology - its contribution to understanding of the etiology, pathogenesis, and prevention of diabetes mellitus. In: Creutzfeldt W, Lefebvre P (eds) Diabetes mellitus: pathophysiology and therapy. Springer, Berlin Heidelberg New York, pp 5-26

3. Mann JI, Houston AC (1983) The aetiology of non-insulin-dependent diabetes mellitus. In: Mann JI, Pyorala K, Teuscher A (eds) Diabetes in epidemiological perspective. Churchill Livingstone, Edinburgh London Melbourne New-York, pp 122-164
4. Zimmet P (1982) Type 2 (non-insulin-dependent) diabetes - an epidemiological overview. Diabetologia 22:399-411

5. Knowler WC, Pettitt DJ, Savage PJ, Bennett PH (1981) Diabetes incidence in Pima Indians: contributions of obesity and parental diabetes. Am J Epidemiol 113: 144-156

6. Taylor R, Thoma K (1985) Mortality patterns in the modernized Pacific island nation of Nauru. Am J Public Health 75: 149-155

7. WHO Expert Committee on Diabetes Mellitus (1980) Second report. WHO Tech. Rep. Ser., no 646. Geneva: World Health Organization

8. Kissebah AH, Vydelingum N, Murray R et al. (1982) Relation of body fat distribution to metabolic complications of obesity. J Clin Endocrinol Metab 54: 254-260

9. Krotkiewski M, Björntorp P, Sjöström L, Smith U (1983) Impact of obesity on metabolism in men and women. Importance of regional adipose tissue distribution. J Clin Invest 72: 11501162

10. Kissebah AH, Evans DJ, Peiris A, Wilson CR (1985) Endocrine characteristics in regional obesities: role of sex steroids. In: Vague J, Björntorp P, Guy-Grand B, Rebuffé Scrive M, Vague P (eds) Metabolic complications of human obesities. Elsevier, Amsterdam, pp 115-130

11. Després JP, Nadeau A, Tremblay A et al. (1989) Role of deep abdominal fat in the association between regional adipose tissue distribution and glucose tolerance in obese women. Diabetes 38 : 304-309

12. Vague J (1956) The degree of masculine differentiation of obesities: a factor determining predisposition to diabetes, atherosclerosis, gout, and uric calculous disease. Am J Clin Nutr 4: 20-34

13. Hartz AJ, Rupley DC, Kalkhoff RD, Rimm AA (1983) Relationship of obesity to diabetes: influence of obesity and body fat distribution. Prevent Med 12: 351-357

14. Haffner SM, Stern MP, Hazuda HP, Pugh J, Patterson JK (1987) Do upperbody and centralized adiposity measure different aspects of regional body-fat distribution? Relationship to non-insulin-dependent diabetes mellitus, lipids and lipoproteins. Diabetes 36: 43-51

15. Björntrop $P$ (1991) Metabolic implications of body fat distribution. Diabetes Care 14: 1132-1143

16. Kissebah AH, Peiris AN, Evans DJ (1988) Mechanisms associating body fat distribution to glucose intolerance and diabetes mellitus: window with a view. Acta Med Scand [Suppl] 723: 79-89

17. West KM (1978) Epidemiology of diabetes and its vascular lesions. Elsevier, New York

18. Modan M, Karasik A, Halkin H (1986) Effect of past and concurrent body mass index on prevalence of glucose intolerance and Type 2 (non-insulin-dependent) diabetes and on insulin response; the Israeli study of glucose intolerance, obesity and hypertension. Diabetologia 29: 82-89

19. Köbberling J, Tillil H, Lorenz HJ (1985) Genetics of type 2Aand type 2B-diabetes mellitus. Diab Res Clin Pract 11 [Suppl 1]: S311 (Abstract)

20. Barnett AH, Eff C, Leslie RD, Pyke DA (1981) Diabetes in identical twins: a study of 200 pairs. Diabetologia 20: 87-93

21. Newman B, Selby JV, King MC, Slemenda C, Fabsitz R, Friedman GD (1987) Concordance for Type 2 (non-insulin-dependent) diabetes mellitus in male twins. Diabetologia 30: 763-768

22. Fujimoto WY, Leonetti DL, Newell-Morris L, Shuman WP, WahI PW (1990) Relationship of absence or presence of a family history of diabetes to body weight and body fat distribution in Type 2 diabetes. Int J Obesity 15: 111-120

23. DeFronzo R (1988) The triumvirate: $\beta$-cell, muscle, liver. A colIusion responsible for NIDDM. Diabetes 37:667-687

24. National Diabetes Data Group (1979) Classification and diag.nosis of diabetes mellitus and other categories of glucose intolerance. Diabetes 28: 1039-1057

25. Behnke AR, Wilmore JH (1974) Evaluation and regulation of body build and composition. Englewood Cliffs: Prentice-Hall, pp 20-37 
26. Meneely GR, Kaltreider NL (1949) Volume of the lung determined by helium dilution. J Clin Invest 28: 129-139

27. Siri WE (1956) The gross composition of the body. Adv Biol Med Phys 4: 239-280

28. The Airlie (VA) consensus conference (1988) In: Lohman T, Roche A, Martorel R (eds) Standardization of anthropometric measurements. Human kinetics publishers, Champaign, pp 39-80

29. Sjöström L, Kvist H, Cederblad A, Tylen U (1986) Determination of total adipose tissue and body fat in women by computed tomography, ${ }^{40} \mathrm{~K}$, and tritium. Am J Physiol 250: E736-E745

30. Ferland M, Després JP, Tremblay A et al. (1989) Assessment of adipose tissue distribution by computed axial tomography in obese women: association with body density and anthropometric measurements. Br J Nutr 61: 139-148

31. Kvist H, Tylen U, Sjöström L (1986) Adipose tissue volume determinations in women by computed tomography. Technical considerations. Int J Obesity 10: 53-67

32. Richterich R, Dauwalder H (1971) Zur bestimmung der plasmaglukosekonzentration mit der hexokinase-glucose-6-phosphatdehydrogenase-methode. Schweiz Med Wochenschr 101: 615618

33. Desbuquois B, Aurbach GD (1971) Use of polyethylene glycol to separate free and antibody-bound peptide hormones in radioimmunoassays. J Clin Endocrinol Metab 37: 732-738

34. Tattersall RB, Pyke DA (1972) Diabetes in identical twins. Lancet II, 1120-1125

35. Serjeantson S, Zimmet P (1984) Diabetes in the Pacific: evidence of a major gene. In: Baba S, Gould M, Zimmet P (eds) Diabetes mellitus: recent knowledge of aetiology, complications and treatment. Academic Press, Sydney, pp 23-30

36. Yamashita TS, Mackay W, Rushforth NB, Bennett PH, Houser $\mathrm{H}$ (1984) Pedigree analysis of non-insulin-dependent diabetes in the Pima Indians suggest dominant mode of inheritance. Am J Hum Genet 36: [Suppl] 183s (Abstract)

37. Park KS, Rhee BD, Lee K-U et al. (1991) Intra-abdominal fat is associated with decreased insulin sensitivity in healthy young men. Metabolism 6: 600-603
38. Sparrow D, Borkan GA, Gerzof SG, Wisniewski C, Silbert CK (1986) Relationship of fat distribution to glucose tolerance: results of computed tomography in male participants of the Normative Aging Study. Diabetes 35: 411-415

39. Fujioka S, Matsuzawa Y, Tokunaga K, Tarui S (1987) Contribution of intra-abdominal fat accumulation to the impairment of glucose and lipid metabolism in human obesity. Metabolism 36: $54-59$

40. Pouliot MC, Després JP, Nadeau A et al. (1992) Visceral obesity in men: associations with glucose tolerance, plasma insulin and lipoprotein levels. Diabetes (in press)

41. Felber JP, Golay A, Jéquier E et al. (1988) The metabolic consequences of long-term human obesity. Int J Obesity 12:377-389

42. Golay A, Felber JP, Jéquier E, DeFronzo RA, Ferrannini E (1988) Metabolic bases of obesity and non-insulin dependent diabetes mellitus. Diab Metab Rev 4: 727-747

43. Saad MF, Knowler WC, Pettitt DJ, Nelson RG, Mott DM, Bennett PH (1988) The natural history of impaired glucose tolerance in the Pima Indians. N Engl J Med 319: 1500-1506

44. Felber JP, Golay A, Felley CH, Jéquier E (1988) Regulation of glucose storage in obesity and diabetes: metabolic aspects. Diab Metab Rev 4:691-700

45. Jallut D, Golay A, Munger R et al. (1990) Impaired glucose tolerance and diabetes in obesity: a 6-year follow-up study of glucose metabolism. Metabolism 10: 1068-1075

Received: 12 December 1991

and in revised form: 16 March 1992

Dr. J.-P.Després

Physical Activity Sciences Laboratory

PEPS, Laval University

Ste-Foy, Québec G1K 7P4

Canada 